\title{
Estratégias no estágio curricular em Psicologia durante a pandemia: caminhos até a
}

\section{proposta nacional}

\author{
Strategies in the curricular internship in Psychology during pandemia: pathways to the national
}

proposal

Estrategias en la práctica curricular de Psicología durante la pandemia: caminos hacia la propuesta nacional

\author{
Ágnes Cristina da Silva Pala \\ ORCID: https://orcid.org/0000-0002-3158-4702 \\ Faculdade Maria Thereza, Brasil \\ Universidade Federal Fluminense, Brasil \\ E-mail: agnespala@gmail.com \\ Marcello Furst de Freitas Accetta \\ ORCID: https://orcid.org/0000-0001-5976-0352 \\ Universidade do Estado do Rio de Janeiro, Brasil \\ E-mail: marcelloffaccetta@gmail.com
}

\begin{abstract}
Resumo
O presente trabalho apresenta o percurso de construção de estratégias e a execução da proposta de estágio em Psicologia de forma remota, desenvolvida ao longo do primeiro semestre de 2020, em uma universidade da cidade do Rio de Janeiro, por conta da pandemia de COVID-19. Com abordagem qualitativa, através de pesquisa documental nos registros das reuniões desenvolvidas com gestão acadêmica, docentes supervisores e discentes, dos documentos oficiais publicados pelo Ministério da Educação, Conselho Nacional de Educação, Conselho Nacional de Saúde, Conselho Federal de Psicologia e Associação Brasileira de Ensino de Psicologia, propomos reflexões e expomos tensões ético-políticas no contexto inicial da pandemia e suas interfaces com o ensino. A construção da proposta para a referida universidade foi inspirada nas Diretrizes Curriculares Nacionais dos cursos de graduação em Psicologia e nos Princípios Fundamentais do Código de Ética do Profissional Psicólogo no que tange outros fazeres profissionais como elaboração de cartilhas e ebooks, montagem de roteiro e gravação de podcast, rodas de conversa. Concluímos que a adaptação dos fazeres e a construção de novos fazeres para o estágio curricular no formato remoto, elaborados pelos autores, passaram a ser, em sua grande maioria, recomendadas em cartilha divulgada em agosto/2020 pela Associação Brasileira de Ensino em Psicologia e pelo Conselho Federal de Psicologia como orientação de práticas de estágio para o segundo semestre de 2020 ou enquanto durar o estado de excepcionalidade da pandemia.
\end{abstract}

Palavras-chave: Psicologia; Ensino; Formação; Estágio; Pandemia; Infecções por Coronavírus.

\begin{abstract}
The present work presents the strategy-building path and the execution of the Psychology internship proposal remotely, developed over the first semester of 2020, at a university in the city of Rio de Janeiro, due to the COVID-19 pandemic. With a qualitative approach, through documentary research on the records of meetings held with academic management, supervisory professors and students, the official documents published by the Ministério da Educação, the Conselho Nacional de Educação, the Conselho Nacional de Saúde, the Conselho Federal de Psicologia and the Associação Brasileira de Ensino de Psicologia, we propose reflections and we expose ethical-political tensions in the initial context of the pandemic and its interfaces with teaching. The construction of proposal for that university was inspired by the National Curriculum Guidelines for undergraduate courses in Psychology and the Fundamental Principles of the Code of Ethics for the Professional Psychologist regarding other activities of the psi professional, such as the preparation of booklets and ebooks, the setting up of a script and podcast recording, circles of conversation. The adaptation of the tasks and the construction of new tasks for the curricular internship in the remote format started to be, for the most part, recommended in a booklet published in August / 2020 by the Associação Brasileira de Ensino de Psicologia and by the Conselho Federal de Psicologia as guidance of internship practices for the second half of 2020 or while the pandemic is in an exceptional state.
\end{abstract}

Keywords: Psychology; Teaching; Training; Internship; Pandemic; Coronavirus Infections. 


\begin{abstract}
Resumen
El presente trabajo presenta la ruta de construcción de estrategia y la ejecución de la propuesta de pasantía de Psicología de manera remota, desarrollada durante el primer semestre de 2020, en una universidad de la ciudad de Río de Janeiro, debido a la pandemia de COVID-19. Con un enfoque cualitativo, a través de la investigación documental de los registros de reuniones mantenidas con la dirección académica, profesores supervisores y estudiantes, los documentos oficiales publicados por el Ministério da Educação, el Conselho Nacional de Educação, el Conselho Nacional de Saúde, el Conselho Federal de Psicologia y la Associação Brasileira de Ensino em Psicologia, proponemos reflexiones y exponemos tensiones ético-políticas en el contexto inicial de la pandemia y sus interfaces con la enseñanza. La construcción de la propuesta para esa universidad fue inspirado en los Lineamientos Curriculares Nacionales para las carreras de Licenciatura en Psicología y los Principios Fundamentales del Código de Ética del Psicólogo Profesional en relación con otras actividades del profesional psi, como la elaboración de folletos y libros electrónicos, la puesta en marcha de un guión y grabación de podcast, Círculos de conversación. La adecuación de las tareas y la construcción de nuevas tareas para la pasantía curricular en el formato remoto comenzó a ser recomendada, en su mayor parte, en un folleto publicado en agosto / 2020 por la Associação Brasileira de Ensino em Psicologia y por el Conselho Federal de Psicologia como guía de prácticas de pasantías para el segundo semestre de 2020 o mientras la pandemia se encuentre en un estado excepcional.
\end{abstract}

Palabras clave: Psicología; Ensenãnza; Formación; Prácticas; Pandemia; Infecciones por Coronavirus.

\title{
1. Introdução
}

Em 26 de fevereiro de 2020, houve a confirmação oficial do primeiro caso de COVID-19 na cidade de São Paulo e, o vírus SARS-CoV-2 foi se espalhando de modo progressivo e intenso pelos 26 estados e distrito federal do país (Souza, 2020). Passados 16 dias, o Governo do Estado do Rio de Janeiro publicou o Decreto ${ }^{\circ} 46.970$, em 13 de março, com o primeiro conjunto de medidas temporárias com caráter preventivo ao contágio, dentre eles: suspensão de aulas em escolas e universidades, e cancelamento de eventos e atividades com presença de público - tais como shows, feiras, e eventos esportivos (Rio de Janeiro - Estado, 2020). A suspensão das aulas em universidades em outros governos estaduais e o avanço da pandemia no território nacional levaram o Ministério da Educação (MEC) a publicar a Portaria MEC n 343/202011 em 17 de março, dispondo sobre a substituição das aulas presenciais por aulas em meios digitais durante a pandemia. $\mathrm{O}$ terceiro parágrafo desta Portaria veda a aplicação da substituição às práticas profissionais de estágios e de laboratórios. (Brasil, 2020)

Por estarmos falando de um curso de graduação em Psicologia de uma IES com dois campi localizados na cidade do Rio de Janeiro, consultamos as Diretrizes Curriculares Nacionais (DCN) para encontrar possíveis saídas e construir estratégias para outras práticas de estágio, sem deixar cumprir os preceitos normativos do Conselho Federal de Psicologia (CFP), haja visto que o docente supervisor precisa ter registro ativo em seu Conselho profissional. No Art. 21 das DCN (Brasil, 2011), encontra-se argumentos para a formulação de outras atividades para os campos de estágio condizentes com a realidade do profissional de psicologia $(p s i)^{2}$. E, no Código de Ética do Profissional Psicólogo - Resolução CFP nº 010/2005 -, há duas argumentações importantes nos Princípios Fundamentais V e VI.

Em março e abril de 2020, as coordenações de curso e de estágio realizaram reuniões com a direção da IES e, também com os docentes supervisores e os discentes estagiários para a construção de estratégias de outras práticas possíveis de estágio. O que chamamos de estratégias são práticas psicológicas que utilizam Tecnologias da Informação e da Comunicação (TICs) como modo de exercício profissional: elaboração de cartilhas e ebooks sobre temas da ciência psicológica e psicopatologias; montagem de roteiro e gravação de podcast; rodas de conversa. No nosso cenário acadêmico, tais atividades exigem a participação, supervisão e presença dos supervisores em suas respectivas execuções. Esta exigência está atrelada,

\footnotetext{
${ }^{1}$ A Portaria MEC no 343/2020 foi alterada, em 19 de março, para Portaria MEC no 345/2020. O disposto pela Portaria MEC no 343 foi postergado por mais 30 dias pela Portaria MEC n ${ }^{\circ} 395 \mathrm{em} 15$ de abril, e posteriormente por mais 30 dias pela portaria 473 em 12 de maio. A Portaria MEC $\mathrm{n}^{\circ} 544 / 2020$, de 16 de junho, prorroga até o dia 31 de dezembro de 2020 a substituição das aulas presenciais por aulas em meios digitais, enquanto durar a situação de pandemia.

2 Abreviação utilizada em textos clássicos, acadêmicos e documentos oficiais da Psicologia brasileira para referir-se aos vocábulos psicologia, psicólogo(a), psicológicas.
} 
especialmente, ao que rege as Resoluções CFP n ${ }^{\circ}$ 011/2018 e a 04/2020 - sobre exercício profissional com TICs ser exercido por portador de registro no CRP.

Um aspecto considerado como possível problema para o sucesso da prática remota de estágio era a qualidade de acesso à internet dos discentes. Porém, a IES estabeleceu uma parceria com empresa de telefonia para garantir acesso aos discentes em função das aulas em forma síncrona. Com esta ação institucional, poucos foram os casos de dificuldade de acesso e, que foram mapeados pelos supervisores e coordenadores e, deste modo, foram construídas outras estratégias de comunicação e interação.

A possibilidade de os cursos de graduação em Psicologia desenvolverem atividades de estágio só se tornou possível a partir de 28 de abril, quando o Conselho Nacional de Educação (CNE) aprova o Parecer CNE/CP n 05/2020 ${ }^{3}$ sobre a Reorganização do Calendário Escolar e da possibilidade de cômputo de atividades não presenciais para fins de cumprimento da carga horária mínima anual (Brasil, 2020b). A partir deste documento, houve reuniões do Núcleo da Associação Brasileira de Ensino em Psicologia-Rio (Núcleo ABEP-Rio), em maio e junho, para debater as possibilidades e as dificuldades dos docentes e coordenadores naquele momento tão excepcional. Em julho, foram realizados Seminários com os Núcleos ABEP do país com a participação dos Conselhos Regionais de Psicologia (CRP) para traçar possíveis estratégias de ação para os estágios. No final do referido mês, o CFP e a ABEP-Nacional realizaram o Seminário Nacional com a apresentação da compilação das propostas regionais e orientações a serem seguidas no âmbito nacional para realização dos estágios por via remota no segundo semestre de 2020.

Neste sentido, apontamos para o vanguardismo e ousadia de implementação de nossas ações ainda no mês de abril/2020, considerando documentos oficiais que embasam as práticas educacionais e de ensino de Psicologia. Percebemos, portanto, que nossa estratégia de práticas de estágio remoto pode ser pensadas como novos modos de oferecimento de estágio mesmo após o contexto pandêmico, por se tratar de práticas de profissionais psis. Neste sentido, corroboramos com Rodrigues et al. (2020) ao apontarem a necessidade de "utilizar técnicas que possam viabilizar a transmissão de informações acerca do cuidado da saúde mental no contexto de pandemia."

\section{Metodologia}

Este artigo propõe a apresentação do caminho percorrido pelos coordenadores de curso e de serviço de psicologia aplicada na construção de uma proposta de estágio na modalidade remota em Psicologia. Foi realizada análise de documentos: registros de atas e gravações de vídeos das reuniões entre coordenadores e, coordenadores e supervisores desenvolvidas no primeiro semestre de 2020; documentos oficiais publicados pelas instâncias orientadoras - Conselho Federal de Psicologia (CFP) e Associação Brasileira de Ensino em Psicologia (ABEP) - e; decretos e pareceres oficiais de instâncias governamentais - Ministério da Educação, Conselho Nacional de Educação (CNE) e Conselho Nacional de Saúde (CNS).

Metodologicamente, o artigo tem uma abordagem qualitativa, considerando "a interpretação por parte do pesquisador com suas opiniões sobre o fenômeno em estudo" (Pereira et.al., 2018, p. 67), com a realização de pesquisa documental entendida por consulta a fontes primárias "levantamento de textos, que se caracterizam por ser de "primeira mão" (Bastos, 2009, p.95). Estes documentos são encontrados em "arquivos públicos, sejam federais, estaduais ou municipais...: decretos, leis, ofícios...; com relação às entidades e instituições de ordem privada, tais como bancos, escolas...: atas, comunicados, ofícios." (Andrade, 1995, p. 24 citado por Bastos, 2009, p. 96)

\footnotetext{
${ }^{3}$ A homologação deste parecer ocorreu, parcialmente, em $1^{\circ}$ de junho de 2020. Em 08 de junho, é aprovado um reexame do Parecer CNE/CP $n^{\circ}$ 05/2020 - Parecer CNE/CP n ${ }^{\circ}$ 09/2020 -, sendo homologado em 09 de julho.
} 


\section{Resultados}

\section{A construção de propostas de atividades remotas de estágio.}

Em concordância com o compromisso ético posto pelas Resoluções do CFP, com os pontos destacados anteriormente em nossas DCN e em consonância com as normativas do MEC, CNE e CNS, a carga horária de todos os níveis de estágio foi dividida em atividades de produção de documentos técnicos; produção de material didático-informativo; elaboração de roteiros de entrevista; análise de clima; análise institucional; elaboração de pesquisa; produção de comunicações orais que visassem a continuidade do processo formativo profissional. A proposta da divisão de horas por atividades também levou em consideração o tempo de produção de relatórios para documentação das atividades e aprovação nos respectivos estágios.

A proposta construída pelos coordenadores foi apresentada e debatida com a equipe de professores supervisores e com o corpo discente, preocupados com a Portaria MEC n 343/2020, que vedava as práticas de estágio. Houve o entendimento de a proposta contemplar outras esferas da formação profissional e manter a relação com os campos de atuação/estágio, apesar do distanciamento físico. A concordância se deu, em grande parte, pela coerência das sugestões de atividades que compunham a proposta e pelos prováveis prejuízos com a suspensão de todas as práticas de estágios. Os possíveis prejuízos poderiam ser: possível suspensão dos contratos dos supervisores; acúmulo de atividades para o próximo semestre; precarização das relações institucionais; atraso nas formaturas; reposição das atividades de maneira insuficiente nos semestres seguintes; impossibilidade de conclusão da graduação por conta de financiamentos estudantis; prejuízo no processo de ensino-aprendizagem. A proposta das atividades de estágio foi apresentada e aprovada pelo Núcleo Docente Estruturante (NDE) e, posteriormente, pelo Colegiado do curso.

As atividades de estágio foram planejadas, coletivamente, pelo professor supervisor e cada turma de estágio, acolhendo interesses diversos e propostas condizentes com o nível de desenvolvimento acadêmico, estando em consonância com as ênfases curriculares do Projeto Pedagógico do Curso (PPC) do curso. Tais atividades consideraram o registro dos discentes e dos docentes na plataforma Google, com acesso às ferramentas digitais por meio do e-mail institucional. Os tutoriais de capacitação no ambiente virtual dos docentes e discentes foram intensificados, apesar da implementação e uso da plataforma pela instituição ter ocorrido em 2018, além de instalação de grupos de discussão virtuais.

Um ponto avaliado como possível problema para a execução da proposta, por parte dos discentes, era o acesso à internet, considerando a qualidade de acesso. Neste sentido, a IES desenvolveu parceria com uma empresa de telefonia com acesso a baixo custo para os discentes matriculados. Ainda assim, outras estratégias individualizadas foram encaminhadas pelos supervisores e coordenação do curso, por exemplo: acesso via mensagens de texto de aplicativos, e-mails, envio de áudios. Tais estratégias visaram minimizar os efeitos das desigualdades sociais já presentes no modelo regular de ensino prépandemia e, que no cenário de isolamento e distanciamento sociais foram intensificados.

As atividades de estágio passaram a ser desenvolvidas em meados do mês de abril, visando manter o corpo discente envolvido na adaptação, construção e desenvolvimento de suas práticas profissionais. No dia 28 do mesmo mês, é aprovado e divulgado o Parecer CNE/CP n05/2020, sendo homologado em $1^{\circ}$ de junho, trazendo orientações para "cômputo de atividades não presenciais para fins de cumprimento da carga horária mínima atual” (Brasil, 2020b, p. 1). Este parecer enfatiza o desenvolvimento de práticas profissionais por meio de estágios em cursos diversos da área da Saúde, por serem permeadas por atividades simuladas e reais com utilização de Tecnologias da Informação e da Comunicação (TICs), embasadas no PPC. Com este parecer, toda a estratégia elaborada para o estágio obrigatório foi indicada como possibilidade para os cursos de 
Psicologia, tendo respaldo com a publicação da Portaria MEC n ${ }^{\circ}$ 544/2020 de 16 de junho, autorizando a substituição das aulas presenciais por aulas em meios digitais até o dia 31 de dezembro de 2020 (Brasil, 2020c).

\section{De propostas e estratégias na tela às práticas remotas: novas possibilidades na formação.}

As práticas remotas de estágio contemplaram as atividades: elaboração de estudo de casos clínicos já atendidos nos semestres anteriores; revisão bibliográfica sobre temas para elaboração de podcasts, cartilhas e ebooks; roteiros de entrevistas; elaboração e desenvolvimento de roteiros e textos de podcast, ebooks e cartilhas. Todas as atividades seguiram este protocolo de implementação e acompanhamento:

1 - Reunião com os docentes supervisores de estágio para desenvolvimento das ações práticas de forma remota;

2 - Delimitação do produto a ser desenvolvido por cada nível de estágio;

3 - Orientação em supervisão do processo de criação dos produtos;

4 - Elaboração dos produtos;

5 - Avaliação dos produtos;

6 - Divulgação e distribuição para o campo/público destinado do estágio.

Os discentes matriculados nas disciplinas de estágio curricular passaram a desenvolver material informativo para população, disponibilizados por meio de cartilhas, e-books e podcasts. Foram iniciadas atividades de pesquisa e de produção científica visando o aprendizado de competências próprias da atividade profissional e o desenvolvimento para a vida cidadã e para o exercício da profissão. Todas as turmas permaneceram com as atividades de supervisão em horário síncrono com os inscritos nas disciplinas por meio do Google Classroom e Google Meet e desenvolveram práticas concernentes a produção de documentos técnicos produzidos pelos psicólogos.

No primeiro semestre de 2020, foram desenvolvidos vinte e cinco podcasts e oito cartilhas informativas, envolvendo os estágios de Psicologia do Esporte; Psicologia em Saúde Mental; Psicologia Hospitalar; Psicologia Clínica; Psicologia Jurídica; Psicologia Comunitária.

As atividades de podcast e produção de material informativo consideraram experiências e práticas desenvolvidas em semestres anteriores com o campo para a produção. Foram desenvolvidas parcerias das equipes de estágios com outros cursos da IES. O curso de graduação em Comunicação Social auxiliou nas gravações e edições dos podcasts, além da criação de canal de veiculação e, o setor de Marketing da instituição fez a divulgação nas redes sociais. O estágio em Psicologia Organizacional, juntamente com o setor de Recursos Humanos da universidade, participou de análise de clima institucional e de um projeto de intervenção e atenção psicológica para apoio aos colaboradores desligados ao longo da pandemia. Estas parcerias apontam para a competência e relevância de o graduando de Psicologia atuar inter- e multidisciplinarmente na execução de suas atividades.

Também foram realizadas três rodas de conversa virtuais, através do Google Meet, com grande participação da comunidade do entorno da universidade, em especial moradores do Complexo da Maré, além da comunidade acadêmica. Os temas das rodas foram racismo; ansiedade e; produtividade - sempre envolvendo reflexões com o momento da pandemia.

Todas as atividades e práticas remotas desenvolvidas contaram com recursos de infraestrutura ofertadas pela instituição, como o Google Meet; Zoom; Google Classroom; Google Docs, além da orientação das coordenações do curso e do SPA no acesso à intranet da universidade.

\footnotetext{
${ }^{4}$ Dispõe sobre a substituição das aulas presenciais por aulas em meios digitais, enquanto durar a situação de pandemia do novo coronavírus Covid-19, e revoga as Portarias MEC n 343, de 17 de março de 2020, nº 345, de 19 de março de 2020, e nº 473, de 12 de maio de 2020.
} 


\section{Discussão}

\section{O contexto social}

Pertencente a uma Instituição de Ensino Superior (IES) tradicional da cidade do Rio de Janeiro, o curso de Psicologia está instalado em dois campi localizados na Zona Norte e na Zona Oeste do município. O perfil do curso é inspirado e adequado ao contexto sócio-regional destas regiões e está em constante formulação de novos conhecimentos através da realidade de seus egressos. Em parte, em função da localização dos campi, o curso de Psicologia teve uma grande abrangência na captação de alunos advindos de parques industriais da Baixada Fluminense, mais especificamente, dos municípios de Duque de Caxias e de Nova Iguaçu. A partir das ações de projetos de extensão, a IES consolida e aperfeiçoa o processo de crescimento da cidadania dos universitários, da comunidade e de instituições parceiras presentes nos arredores e nas cidades vizinhas.

Em 2018, com a atualização do PPC e da estrutura curricular, a IES iniciou parceria com a Google dispondo das ferramentas ${ }^{5}$ para o desenvolvimento de conteúdo e do processo de ensino-aprendizagem. Tal ação possibilitou ao docente e discente um contato mais próximo e o acompanhamento remoto de atividades pedagógicas. Além de disponibilizar o acesso gratuito à uma série de recursos digitais para o corpo discente, a IES desenvolveu uma série de capacitações para o uso das ferramentas através do ambiente virtual do aluno, possibilitando a inserção digital e a democratização do conhecimento. Com este recurso implementado, as ações de capacitação foram essenciais para a continuidade das atividades acadêmicas no primeiro semestre do ano de 2020 e o desenvolvimento de novas ações pedagógicas.

\section{Argumentações e justificativas para práticas remotas de estágio.}

As IES precisaram posicionar-se sobre práticas remotas de estágio em função do contexto pandêmico e, segundo as realidades institucionais, mesmo não havendo garantia de plataforma 100\% segura e, ainda, não tendo uma construção sólida de prática online. As coordenações de curso e de estágios precisaram pensar ações em consonância com os compromissos éticos da Psicologia brasileira e da Educação. Neste sentido, decisões diversas foram tomadas sobre as práticas de estágios: suspensão total; suspensão parcial; adaptação e criação de outras práticas. Ao ressaltar este último posicionamento, destaca-se a manutenção do calendário letivo, sem a garantia de acesso e capacitação plena dos discentes e docentes, e de aprovação e validação pelas instâncias reguladoras.

Na IES em que atuamos no primeiro semestre de 2020, a continuidade das práticas de estágio corresponde a uma série de pontos interseccionais: a qualidade do processo ensino-aprendizagem; as diversas formas de desigualdades sociais; a precarização da atividade docente; a crescente implementação de cursos e disciplinas em formato de Educação à Distância (EaD) já presentes antes de 2020. Especificamente, neste período pandêmico, as demandas institucionais mais urgentes eram ações de continuidade do processo de ensino-aprendizagem de qualidade e excelência, a manutenção dos empregos docentes, a promoção da saúde mental e a assistência à população acadêmica e à comunidade de seus arredores.

Nossos questionamentos, enquanto coordenadores, eram sobre as medidas que seriam adotadas pelo MEC ao longo do primeiro semestre para o cumprimento do calendário letivo e as estratégias possíveis para a IES, caso as atividades de estágio fossem suspensas. Os encontros de supervisão foram mantidos, de forma síncrona, com os horários em que os discentes estavam matriculados, sendo necessário questionar quais as reais possibilidades e impossibilidades de realização de práticas de estágios por meio remoto no cenário pandêmico e de isolamento social. E, se as propostas de atividades e práticas substitutivas aos campos presenciais, seriam reconhecidas pelo MEC, com base nas Diretrizes Curriculares Nacionais (DCN) para os cursos

\footnotetext{
${ }^{5}$ G Suite (antigo Google Apps) é um serviço do Google que oferece versões de seus produtos, podendo ser personalizados de forma independente com o nome de domínio do cliente. G Suite oferece inúmeras ferramentas como Gmail, Hangouts, Google Agenda, Drive, Docs, Planilhas, Apresentações, Groups, News, Play, Sites e Vault.
} 
de graduação em Psicologia em vigor (Brasil, 2011), na Resolução CFP nº 010/2005 - Código de Ética do Profissional Psicólogo e nas orientações da ABEP, CFP e CRP-RJ.

O movimento de construção de propostas de atividades de estágio pelos coordenadores aos professores supervisores e discentes foram embasadas em alguns artigos das DCN. O Art. $3^{\circ}$ versa sobre a formação do psicólogo estar voltada para a atuação, ensino e pesquisa da Psicologia, assegurada com base em aprimoramento e capacitação contínuos. Já o Art. $4^{\circ}$ apresenta objetivos da formação em Psicologia, destacando a necessidade de desenvolvimento de habilidades e competências gerais, dentre elas, a tomada de decisões pois o exercício da profissão de psicólogo(a) "deve estar fundamentado na capacidade de avaliar, sistematizar e decidir as condutas mais adequadas, baseadas em evidências científicas" (Brasil, 2011, p. 2), além da relevância da educação permanente para a formação de profissionais responsáveis e compromissados, também, com a formação e "treinamento de futuras gerações de profissionais". (Brasil, 2011, p. 2) Neste sentido, a reflexão de Pereira, Pereira e Nunes (2020) condiz com as nossas estratégias para ações de estágios curriculares:

cabe, portanto, às IES a função de avaliar e de renovar a Clínica-escola, de modo que estudantes estagiários sejam capacitados e comprometidos em oferecer suporte a sociedade, visto que estas instituições são incumbidas em proporcionar a formação de Psicólogos de elevada qualificação e, nessa concepção, deve-se formar cidadãos aptos de atuar diante das demandas típicas do século XXI.. (Pereira, Pereira \& Nunes, 2020, p.25)

As competências previstas pelas DCN reportam a desempenhos e atuações requeridas do graduado em Psicologia, e devem garantir ao profissional o domínio básico de conhecimentos psicológicos e a capacidade de utilizá-los em diferentes contextos. Dentre as quinze competências listadas no Art, $8^{\circ}$, ressaltamos as três competências que embasaram a proposta de continuidade das atividades de estágio:

IX- atuar inter e multiprofissionalmente, sempre que a compreensão dos processos e fenômenos envolvidos assim o recomendar;

XI - atuar, profissionalmente, em diferentes níveis de ação, de caráter preventivo ou terapêutico, considerando as características das situações e dos problemas específicos com os quais se depara; XIII - elaborar relatos científicos, pareceres técnicos, laudos e outras comunicações profissionais, inclusive materiais de divulgação; apresentar trabalhos e discutir ideias em público.” (Brasil, 2011, p. 3).

Sobre os estágios supervisionados em Psicologia, o Art. 21 pauta que estes "visam assegurar o contato do formando com situações, contextos e instituições, permitindo que conhecimentos, habilidades e atitudes se concretizem em ações profissionais, sendo recomendável que as atividades do estágio supervisionado se distribuam ao longo do curso." (Brasil, 2011. p.7). Tais atividades de formação devem assegurar a consolidação e a articulação das competências estabelecidas nas DCN.

A Resolução CFP nº 010/2005 - Código de Ética do Profissional Psicológico -, orienta em dois Princípios Fundamentais:

IV - o psicólogo atuará com responsabilidade, por meio continuo aprimoramento profissional, contribuindo para o desenvolvimento da Psicologia como campo científico de conhecimento e de prática.

V - o psicólogo contribuirá para promover a universalização do acesso da população às informações, ao conhecimento da ciência psicológica, aos serviços e aos padrões éticos da profissão. (Conselho Federal de Psicologia, 2005, p. 7).

Tais Princípios nos alerta para a responsabilidade dos coordenadores de curso, de estágio, docentes e supervisores no que tange a atualização de seu saber e de seu campo de prática. Neste sentido, entende-se que a prática psicológica por meio de Tecnologias da Informação e da Comunicação (TICs) pode ser apresentada, problematizada e, dentro do possível, vivenciada no meio acadêmico. O Princípio Fundamental V traz o argumento necessário para percebermos que elaboração de materiais informativos à população sobre o saber psi é extremamente necessário e passível de ser executado em práticas de estágio. 
Ao considerar as DCN, o Código de Ética, o Projeto Pedagógico do Curso, os marcos legais apresentados e a situação de isolamento social e de saúde pública imposta pela pandemia, avaliamos que a possibilidade de realizar algumas atividades que, futuramente, poderiam ser validadas como carga horária dos estágios curriculares por serem práticas de exercício profissional e disseminação do saber e da ciência psicológica para a população. Ao afirmar que a Psicologia e sua prática não se restringem somente aos atendimentos individualizados e privados, nossos docentes e discentes foram incentivados a adaptar e a construir atividades profissionais para, sobre e com o campo de estágio existente a priori ao período de pandemia.

O Conselho Federal de Psicologia, através da Resolução CFP no 11/2018, regulamenta a prestação de serviços psicológicos por meio de Tecnologia da Informação e da Comunicação (TICs) para os profissionais psicólogos(as). Esta prestação de serviço pode utilizar todas as mediações informacionais e comunicativas com acesso à Internet, via televisão, aparelhos telefônicos, aparelhos conjugados ou híbridos, websites, aplicativos, plataformas digitais ou qualquer outro modo de interação que possa vir a ser implementado (Conselho Federal de Psicologia, 2018). Em 26 de março de 2020, o CFP emitiu a Resolução CFP n ${ }^{\circ}$ 04/2020, fazendo considerações e adaptações ao exercício profissional mediado por TICs durante o período da pandemia do COVID-19 (Conselho federal de Psicologia, 2020a), mas esta normativa e a anterior restringem-se aos profissionais psicólogos(as): não abordam, por exemplo, atividades de estágio com discentes.

Em março e abril, os coordenadores do curso de Psicologia e do Serviço de Psicologia Aplicada (SPA) da referida IES participaram de reuniões com a direção de ensino e gerência de aprendizagem e, realizaram encontros com a equipe de professores supervisores e, também, com o corpo discente para construção de novas práticas de estágio por meio remoto. Além disto, as coordenações participaram de dois encontros promovidos pelo Núcleo ABEP-RJ e mantiveram contato com o Conselho Regional de Psicologia do Rio de Janeiro (CRP-RJ). Tais encontros visavam alinhar os posicionamentos éticopolíticos pautados pelas instâncias orientadoras da formação em Psicologia com as demandas institucionais e, prioritariamente, com os limites e possibilidades dos discentes e docentes.

\section{O que pensa e pode a Psicologia Brasileira?}

Além de duas reuniões organizadas pelo Núcleo ABEP-Rio em maio e junho, participamos do Seminário Regional CRP-RJ e Núcleo ABEP-Rio, em 04 de julho, onde foi debatido as possibilidades e as dificuldades das aulas remotas em grupos de coordenadores, supervisores e discentes. Em todo o país, foram realizados Seminários Regionais com esta proposta de debate e, as atas destes Seminários foram discutidas em uma plenária nacional composta por representantes dos Núcleos ABEP do país e pessoas indicadas pelos CRPs. Desta plenária nacional, há a compilação e construção de documento nacional com orientações sobre estágio curricular em Psicologia. Os resultados da compilação foram divulgados no Seminário Nacional CFP/ABEP sobre estágios curriculares, em 23 de julho de $2020^{6}$.

O Seminário Nacional foi dividido em três momentos - Síntese dos Seminários, Posição do FENPB e Reflexões Finais. Um dos primeiros pontos avaliava que as atividades oferecidas em caráter remoto devem levar em consideração: local de estágio, supervisores, estagiários e público atendido. Nos seminários regionais, foram ressaltados a necessidade de pensar a prática de estágio para além da clínica psicológica. Entretanto, tratando-se deste campo como um dos mais problematizados, postulou-se que é necessário pensar os Serviços de Psicologia mediados por TICs, como a Telepsicologia em práticas de acolhimento, orientação, apoio e plantão psicológico. Além da necessidade da diferenciação e demarcação das formas de execução das atividades enquanto síncrona e assíncrona. (Conselho Federal de Psicologia, 2020b)

Com relação aos que podem ser atendidos remotamente, foi permitida práticas com idosos, jovens, adultos, vítimas de COVID-19, quem demanda psicoterapia, profissionais de linha de frente ao combate à pandemia, mulher vítima violência não

\footnotetext{
${ }^{6}$ Disponível em https://www.youtube.com/watch?v=GEeykYnOOzQ. Acesso em 20 de agosto de 2020.
} 
residindo com o(a) agressor(a). Ficou vedada atividades com crianças e, criança e adolescente vítimas de violência e violência sexual. (Conselho Federal de Psicologia, 2020b)

Foi apresentado o que não pode ser considerado como prática de estágio: atividades sociais e informativas; grupos de estudo; discussão teórica; estudo de caso; análise de filme; simulações; pesquisa científica fora de uma ênfase em processo de investigação; elaborações de documentos - que não esteja vinculado a ações de estágio - como práticas de estágio e, também não devem ocorrer em situações de falta de garantia da guarda de documentos.

Para que tais ações fossem desenvolvidas, a Psicologia brasileira estipulou condições gerais indispensáveis. Dentre elas: respeito aos princípios éticos; observação e zelo quanto ao ambiente e sigilo; capacitação para docentes e discentes; avaliação permanente do impacto do estágio remoto; atenção às características regionais; a obrigatoriedade de o supervisor ter o cadastro de prestação de serviços por meio de tecnologias da informação e comunicação no e-psi, através do site https://epsi.cfp.org.br/. (Conselho Federal de Psicologia, 2020b)

Tais condições exigem dos profissionais e instituições uma adequação dos protocolos, planos de atividades, e materiais para práticas remotas. $\mathrm{O}$ (a) supervisor(a) deve acompanhar as atividades desenvolvidas pelos discentes. Em ação conjunta com a gestão também se pautou a necessidade desses profissionais avaliarem a realidade da acessibilidade do corpo discente, assim como a possibilidade de empréstimo, aquisição de equipamentos por parte da IES aos discentes e, também considerar o aprimoramento de plataformas; internet de qualidade; e a garantia de acesso ao público atendido. Salientou-se também que todas as ações desenvolvidas devem avaliar a saúde mental e bem-estar de docentes e estagiários: condições de trabalho para docente exercer a supervisão; a oferta de equipamentos; oferta de formação e capacitação para docentes e estudante/estagiário; além da importância do constante diálogo com sindicato para garantia de direitos. (Conselho Federal de Psicologia, 2020b)

Percebe-se, portanto, inúmeros aspectos devem ser observados no que tange as implicações destas ações para a formação do futuro psicólogo e para o trabalho docente. Dentre elas: a necessidade de repensar as práticas de estágio, preparando o estagiário para o mercado de trabalho e a necessidade de se pensar em um percentual de desenvolvimento de habilidades e competências de atividades online. (Conselho Federal de Psicologia, 2020b)

Em 25 de agosto, foi divulgado o documento com as orientações para práticas de estágio curricular, apresentadas no Seminário Nacional ${ }^{7}$.

\section{Considerações Finais}

A proposta de práticas remotas de estágio em Psicologia, desenvolvida no primeiro semestre de 2020 na referida IES, garantiu a finalização dos estágios dentro do calendário acadêmico, além da conclusão de curso de todos os formandos, buscando os mínimos prejuízos para o corpo discente, conforme a realidade e condições de todos os envolvidos. Apesar de nós, à época coordenadores do curso de Psicologia e do SPA, não concordarmos integralmente com algumas decisões institucionais, desenvolvemos tal projeto em proximidade e alinhamento com as determinações legais propostas pelo MEC e com as instâncias de orientação ABEP, CFP e CRP-RJ.

Ao entender o processo democrático como tarefa árdua e demorada, buscamos por meio de intensos diálogos, entre todas as instâncias e todos os atores envolvidos no processo, a construção deste caminho apresentado. Nossa resposta ao problema pandêmico esteve orientada por manter a qualidade da formação do(a) futuro(a) psicólogo(a) e, de maneira criativa, manter o engajamento de todos os envolvidos no processo de aprendizagem.

\footnotetext{
${ }^{7}$ Disponível em: http://www.abepsi.org.br/?p=4185. Acesso em 25 de agosto de 2020.
} 
Neste sentido, é perceptível que o desenvolvimento de nossa proposta de continuidade das atividades de estágio de forma remota antecipou, consideravelmente, uma série de definições posteriores advindas por meio dos marcos legais e do processo democrático de discussão com a classe promovida pela ABEP, CRPs e CFP. Esta proposta construída coletivamente foi possível a partir da compreensão do caráter de urgência e exceção em que vivíamos no primeiro semestre de 2020, através do entendimento, da colaboração e da solidariedade de supervisores e estudantes sob efeitos da pandemia, envolvendo angústia, preocupações quanto ao futuro, ao emprego, término da formação e entrada no mercado de trabalho.

A necessidade de pensar o ensino superior em Psicologia no Brasil, a partir de sua diversidade regional, não pode prescindir de maior celeridade e intensa comunicação com os atores envolvidos. Constatamos que propostas similares às nossas não foram apresentadas no Seminário Regional do Estado do Rio de Janeiro, ocorrido em 04 de julho, pois aguardavam posicionamento tutelar das instâncias orientadoras. Ressaltamos a importância de troca constante com as IES, coordenadores de curso e de serviços de psicologia aplicada, docentes e discentes, além da produção de notas oficiais e reuniões, considerando as diferenças essenciais entre o ensino público e privado.

A cautela, a preocupação e a responsabilidade com a qualidade da formação em Psicologia e com a precarização do ofício docente foram manifestadas por diversas instâncias como o Fórum das Entidades da Psicologia Brasileira (FENP), a ABEP, CFP e, também, de uma maneira geral a todos os cursos de Saúde pelo CNS. O compromisso com a formação nos guiou ao final do primeiro semestre de 2020, sem pendências para o corpo discente e sem prejuízos para o corpo docente. As propostas desenhadas para a relação ensino-aprendizagem adaptadas ao contexto de isolamento social passam a ser, em sua grande maioria, recomendadas pela ABEP e CFP para o segundo semestre de 2020 e, com possibilidade de prorrogação para 2021.

Vale apontar que, ao finalizarmos este artigo em 2021, vemos que as IES manterão suas atividades remotas de ensino e de práticas de estágio, ao menos, no primeiro semestre deste ano, em função da continuidade da pandemia e da delicada situação de campanhas de vacinação contra COVID-19. Espera-se que as ofertas de estágio curricular possam ser pensadas de modo mais amplo e liberto da antiga compreensão de áreas/ênfases clínica e social presenciais - respectivamente, atendimentos psicoterapêuticos individuais e em grupo e, intervenção em instituições e comunidade - no sentido de outras modalidades de praticar estas atividades e a realização de outras que, de certo modo, também são práticas psi cumprindo, inclusive, o que preconiza os Princípios Fundamentais IV e V da Resolução CFP nº 010/2005.

Acreditamos, enquanto psicólogos e formadores, que a experiência das diversas modalidades de estágios remotos será importante para a inovação do devir-psicólogo, cabendo melhorias e discussões nos âmbitos regionais e nacional. De todas as atividades propostas pelos autores, construídas e executadas pelos estagiários e supervisores, as que despertam interesse na continuação de nossas reflexões são as rodas de conversa por serem espaços de maior exposição dos participantes/pacientes e de intervenção dos estagiários e, os podcasts por serem espaços de maior alcance à comunidade e população.

\section{Referências}

Bastos, R. L. (2009). Ciências Humanas e Complexidades: projetos, métodos e técnicas de pesquisa - o Caos, a Nova Ciência. E-papers.

Brasil. (2011). Ministério da Educação. Conselho Nacional de Educação. Resolução CNE/CES $n^{o}$ 05. Institui as Diretrizes Curriculares Nacionais para os cursos de graduação em Psicologia, estabelecendo normas para o projeto pedagógico complementar para a Formação de Professores de Psicologia. Brasília. http://portal.mec.gov.br/docman/marco-2011-pdf/7692-rces005-11-pdf

Brasil. (2020a). Ministério da Educação. Gabinete do Ministro. Portaria $n^{o}$ 343, de 17 de março de 2020. Dispõe sobre a substituição das aulas presenciais por aulas em meios digitais enquanto durar a situação de pandemia do Novo Coronavírus - COVID-19. http://www.planalto.gov.br/CCIVIL_03/Portaria/PRT/Portaria\%20n\%C2\%BA\%20343-20-mec.htm

Brasil. (2020b). Ministério da Educação. Conselho Nacional de Educação. Parecer CNE/CP $N^{o}$ 05/2020. Reorganização do Calendário Escolar e da possibilidade de cômputo de atividades não presenciais para fins de cumprimento da carga horária mínima anual, em razão da Pandemia da COVID-19. http://portal.mec.gov.br/index.php?option=com_docman\&view=download\&alias=145011-pcp005-20\&category_slug=marco-2020-pdf\&Itemid=30192 
Research, Society and Development, v. 10, n. 2, e36310212642, 2021

(CC BY 4.0) | ISSN 2525-3409 | DOI: http://dx.doi.org/10.33448/rsd-v10i2.12642

Brasil. (2020c). Ministério da Educação. Gabinete do Ministro. Portaria n ${ }^{\circ} 544$, de 16 de junho de 2020. Dispõe sobre a substituição das aulas presenciais por aulas em meios digitais, enquanto durar a situação de pandemia do novo coronavírus - Covid-19, e revoga as Portarias MEC n 343 , de 17 de março de 2020 , $\mathrm{n}^{\circ}$ 345, de 19 de março de 2020, e no 473, de 12 de maio de 2020. https://www.in.gov.br/en/web/dou/-/portaria-n-544-de-16-de-junho-de-2020-261924872

Conselho Federal de Psicologia. (2005). Resolução CFP no 010/2005. Aprova o Código de Ética Profissional do Psicólogo. Brasília: Conselho Federal de Psicologia.

Conselho Federal de Psicologia. (2018). Resolução CFP $n^{\circ}$ 011/2018. Regulamenta a prestação de serviços psicológicos prestados por meios de tecnologia da informação e da comunicação e revoga a Resolução CFP n ${ }^{\circ}$ 011/2012. Brasília: Conselho Federal de Psicologia. https://atosoficiais.com.br/cfp/resolucao-doexercicio-profissional-n-11-2018-regulamenta-a-prestacao-de-servicos-psicologicos-realizados-por-meios-de-tecnologias-da-informacao-e-da-comunicacao-erevoga-a-resolucao-cfp-n-112012

Conselho Federal de Psicologia. (2020a). Resolução CFP $n^{o}$ 004/2020. Dispõe sobre a regulamentação de serviços psicológicos prestados por meio de Tecnologia da Informação e da Comunicação durante a pandemia do COVID-19. Brasília: Conselho Federal de Psicologia. https://atosoficiais.com.br/cfp/resolucao-do-exercicio-profissional-n-4-2020-dispoe-sobre-regulamentacao-de-servicos-psicologicos-prestados-por-meio-detecnologia-da-informacao-e-da-comunicacao-durante-a-pandemia-do-covid-19?origin=instituicao

Conselho Federal de Psicologia. (2020b). Seminário Nacional: Formação em Psicologia no Contexto da Covid-19. Youtube. 23 ago 2020. https://www.youtube.com/watch?v=GEeykYnOOzQ.

Pereira, A. S. et al. (2018). Metodologia da pesquisa científica. UFSM, https://repositorio.ufsm.br/bitstream/handle/1/15824/Lic_Computacao_MetodologiaPesquisa-Cientifica.pdf?sequence $=1$

Pereira, M. D., Pereira, M. D., \& Nunes, A. K. F. (2020). Estágio curricular supervisionado em Psicologia Clínica à luz das DCNs. Research, Society and Development, 9(8), e440985900. https://doi.org/10.33448/rsd-v9i8.5900

Rio de Janeiro (Estado). (2020) Decreto $n^{\circ} 46.970$ de 13 de março de 2020. Dispõe sobre medidas temporárias de prevenção ao contágio e de enfrentamento da propagação decorrente do novo coronavírus (covid-19), do regime de trabalho de servidor público e contratado, e dá outras providências. https://pge.rj.gov.br/comum/code/MostrarArquivo.php?C=MTAyMjE\%2C.

Rodrigues, J. V. dos S., Cardoso, A. J., Gualberto, L. G. C., Monteiro, J. D., Lima, B. J. M. de \& Cruz, C. R. P. (2020). Estágio supervisionado em Psicologia da Saúde durante a pandemia da COVID-19. Research, Society and Development, 9(9), e680997580. https://doi.org/10.33448/rsd-v9i9.7580

Souza, W. M. de et al. (2020) Epidemiological and clinical characteristics of the early phase of the COVID-19 epidemic in Brazil. https://www.medrxiv.org/content/10.1101/2020.04.25.20077396v1 https://doi.org/10.1101/2020.04.25.20077396 